СОТРУДНИЧЕСТВО ВРАЧЕЙ-СТОМАТОЛОГОВ И ВРАЧЕЙ-ЭНДОКРИНОЛОГОВ

ПО ВОПРОСАМ ВЫЯВЛЕНИЯ И ВЕДЕНИЯ ПАЦИЕНТОВ С САХАРНЫМ ДИАБЕТОМ: АСПЕКТЫ МЕЖДИСЦИПЛИНАРНОГО ВЗАИМОДЕЙСТВИЯ

\author{
() Е.Е. Маслак, В.Н. Наумова
}

Волгоградский государственный медицинский университет, Волгоград

ОБОСНОВАНИЕ. Сахарный диабет (СД) способствует неблагоприятному течению стоматологических заболеваний; в свою очередь, воспалительные заболевания челюстно-лицевой области способны нарушить гликемический контроль и усугубить течение СД. Необходимо комплексное междисциплинарное рассмотрение проблемы больных СД и стоматологическими заболеваниями.

ЦЕЛЬ. Рассмотреть аспекты междисциплинарного взаимодействия врачей-стоматологов и врачей-эндокринологов по выявлению и ведению больных СД.

МЕТОДЫ. Дизайн исследования предполагал изучение мнений врачей-стоматологов и врачей-эндокринологов о взаимодействии в вопросах выявления и ведения больных СД, исследование знаний о СД и комплаентности пациентов стоматологических поликлиник в вопросах выполнения рекомендаций врачей по прохождению эндокринологического обследования, скрининговое обследование стоматологических пациентов для выявления риска и признаков СД. Исследование проводилось в 2015-2016 гг. с использованием методов клинического обследования (оценка стоматологического статуса) и статистического анализа. Всего в исследовании участвовали 432 пациента стоматологических организаций и 433 врача (371 - стоматологи, 62 - эндокринологи), работающие в государственных и негосударственных медицинских организациях. На проведение исследования было получено разрешение Регионального исследовательского этического комитета. У каждого участника исследования было получено письменное информированное согласие на участие в исследовании.

РЕЗУЛЬтАТЫ. Установлены недостаточный уровень взаимодействия врачей-стоматологов и врачей-эндокринологов в выявлении и ведении больных СД, низкая мотивация стоматологических пациентов к эндокринологическому обследованию; подтверждены целесообразность введения скрининга на определение риска СД в алгоритм обследования больных с воспалительными заболеваниями пародонта, необходимость включения врачей-стоматологов в перечень специалистов, консультация которых обязательна при ведении больных с диагнозом «сахарный диабет», целесообразность нормативного закрепления взаимодействия эндокринологов и стоматологов в ведении больных СД, необходимость введения занятий стоматологического профиля в Школу сахарного диабета.

ЗАКЛюЧЕНИЕ. Полученные данные обосновывают необходимость включения в Стандарт медицинской помощи больным СД участия врача-стоматолога в обследовании и ведении больных СД, введения для стоматологических пациентов скрининга на СД в виде анкетирования.

КЛЮЧЕВЫЕ СЛОВА: сахарный диабет; междисциплинарное взаимодействие; стоматология; эндокринология; массовый скрининг

\title{
INTERDISCIPLINARY COOPERATION BETWEEN DENTISTS AND ENDOCRINOLOGISTS FOR IDENTIFICATION AND MANAGEMENT OF DIABETES MELLITUS
}

\author{
(c) Elena E. Maslak, Victoria N. Naumova
}

Volgograd State Medical University, Volgograd, Russia

BACKGROUND: DM mellitus (DM) leads to worsening periodontal diseases, and in turn the inflammatory diseases of maxillofacial region adversely affect the glycemic control and exacerbate the severity of DM, thereby engendering a vicious cycle that compromises the DM management in patients. Taking account of the bidirectional relationship between DM and periodontal disease, interdisciplinary examination of patients with both DM and periodontal diseases is warranted to improve the health outcomes in patients.

AIMS: This study aims to evaluate the perceptions of dentists and endocrinologists on the interdisciplinary cooperation for identification and management of patients with DM.

MATERIALS AND METHODS: Studying patients' knowledge about DM and their compliance in providing endocrinological recommendations, dental screening survey to identify DM' risk and signs The research was done in 2015-2016 years using clinical survey (dental status survey), statistical analysis. 432 patients from different dental organizations and 433 doctors ( 371 - dentists and 62 - endocrinologists) took part in the research. The research was approved by Regional research ethics committee. The written informed consent was taken from each participant. 
RESULTS: There was insufficient interdisciplinary collaboration for identification and management of patients with diabetes, and lack of motivation among dental patients to endocrinological survey. Hence, it is important to incorporate definitive screening for risk of DM for patients with inflammatory periodontal disease and include dentists in consultation for patients with DM. The feasibility of statutory determination of collaboration between specialists in identification and management of patients with DM was found, dental lectures are necessary in DM school.

CONCLUSIONS: Our findings suggest the necessity of including dentists in the standard of medical management of patients with DM and incorporating DM screening by a questionnaire upon dental examination.

KEYWORDS: diabetes mellitus; interdisciplinary cooperation; dentistry; endocrinology; mass screening

Распространенность сахарного диабета (СД) ежегодно увеличивается среди детского и взрослого населения во всех странах мира, включая и Россию [1, 2]. У больных СД 1 и 2 типов, особенно с неконтролируемой гликемией, отмечается тяжелое течение многих стоматологических заболеваний [3]. Учитывая, что у многих больных диабет своевременно не диагностируется [4], актуальной проблемой является улучшение взаимодействия врачей-стоматологов и врачей-клиницистов как по вопросам выявления, так и ведения больных СД $[5,6]$. Однако этой проблеме не уделяется должное внимание [7]. В алгоритмах оказания медицинской помощи больным СД нет указаний на необходимость направления больных на консультацию к врачу-стоматологу [8]. В рекомендациях для врачей-стоматологов также недостаточно внимания уделено оказанию стоматологической помощи больным СД [9]. Для более детального изучения проблемы междисциплинарного взаимодействия специалистов в отношении больных СД было проведено настоящее исследование.

\section{ЦЕЛЬ}

Рассмотреть аспекты междисциплинарного взаимодействия врачей-стоматологов и врачей-эндокринологов по выявлению и ведению больных СД.

\section{МЕТОДЫ}

\section{Дизайн исследования}

Одномоментное одноцентровое нерандомизированное исследование в параллельных группах.

\section{Критерии соответствия}

Наибольшая взаимозависимость выявлена между СД и заболеваниями пародонта, поэтому в исследование комплаентности стоматологических пациентов были включены взрослые посетители пародонтологических кабинетов в возрасте 25-75 лет, давшие согласие на участие в исследовании. В скрининговое исследование риска развития СД были включены стоматологические пациенты в возрасте 35-65 лет, не имевшие декомпенсированных форм соматической патологии, острой боли, требующей оказания немедленной стоматологической помощи, которые подписали согласие на участие в исследовании. Критерии исключения пациентов из исследования: возраст младше 35 и старше 65 лет, наличие декомпенсированных форм соматической патологии, наличие острой боли, требующей оказания немедленной стоматологической помощи, отказ от участия в исследовании. Критерии включения врачей в исследование: наличие сертификата специалиста, стаж работы более одного года, согласие на участие в исследовании. Критерии исключения: отсутствие сертификата специалиста, стаж работы по специальности менее года, отказ от участия в исследовании.

\section{Условия проведения}

В исследование по изучению комплаентности стоматологических пациентов были включены взрослые пациенты различных стоматологических организаций, что позволило оценить мнения по изучаемой проблеме различных слоев населения. Привлечение к анкетированию врачей-стоматологов и врачей-эндокринологов, работавших в 38 различных медицинских и стоматологических организациях, позволило выявить основные проблемы междисциплинарного взаимодействия специалистов и исключить влияние фактора места работы на результаты исследования. Скрининговое обследование стоматологических пациентов с целью выявления СД было проведено в двух государственных стоматологических организациях. В Волгограде - промышленном городе с миллионным населением, - исследование проводили в стоматологической поликлинике Волгоградского государственного медицинского университета, в которой получают стоматологическую помощь жители всех районов города. В выборке представлены пациенты, проживавшие в различных районах Волгограда, работавшие в различных условиях или не работавшие, имевшие разное социально-экономическое положение, культурный и образовательный уровень. Вторая стоматологическая организация - типичная стоматологическая поликлиника малого города Котельниково (40 тыс. жителей), посетители которой представляли весь спектр жителей малых городов и сельской местности области.

\section{Продолжительность исследования}

Анкетирование для оценки комплаентности стоматологических пациентов проводилось в 2015 г., анкетирование врачей-стоматологов и врачей-эндокринологов - в 2015-2016 гг., скрининговое обследование стоматологических пациентов (анкетирование и клиническое обследование) - в 2015-2016 гг.

\section{Описание медицинского вмешательства}

Пациентам стоматологических организаций, врачам-стоматологам и врачам-эндокринологам предлагалось участвовать в исследовании (анкетировании) добровольно и анонимно. Авторские анкеты были разработаны в соответствии с принципами проведения социологических исследований [10]. Для скринингового анкетирования стоматологических пациентов был использован опросник, разработанный И.И. Дедовым и соавт., 2015. После скринингового анкетирования па- 
циенты проходили стандартное стоматологическое обследование, включавшее определение и регистрацию состояния органов и тканей челюстно-лицевой области (данные внешнего осмотра, состояние височно-нижнечелюстных суставов, слюнных желез, слизистой рта, пародонта, окклюзии, зубов, гигиены рта). Использовались стандартные методы визуального, инструментального и дополнительного обследования (визиография).

\section{Основной исход исследования}

Оценка состояния и определение возможности улучшения междисциплинарного взаимодействия врачей-стоматологов и врачей-эндокринологов по вопросам выявления и ведения больных СД.

\section{Дополнительные исходы исследования}

Оценка значимости скрининговых исследований для выявления СД у пациентов стоматологических поликлиник. Оценка значимости стоматологического обследования пациентов с установленным диагнозом СД.

\section{Анализ в подгруппах}

Компаративный анализ результатов скринингового обследования пациентов проводили между двумя подгруппами: жителями г. Волгограда и жителями Волгоградской области. Сравнивали результаты анкетирования врачей-стоматологов и врачей-эндокринологов.

\section{Методы регистрации исходов}

Результаты анкетирования пациентов и врачей, результаты клинического обследования пациентов заносились в электронную базу данных для последующей статистической обработки. Риск развития СД определяли по данным скринингового обследования пациентов (анкетирование). Знания и комплаентность пациентов определяли по данным анкетирования. Взаимодействие врачей-стоматологов и врачей-эндокринологов оценивали по результатам анализа данных анкетирования. Результаты исследования позволили определить возможности улучшения междисциплинарного взаимодействия врачей-стоматологов и врачей-эндокринологов по вопросам выявления и ведения больных СД.

\section{Этическая экспертиза}

Этическая экспертиза была проведена Региональным исследовательским этическим комитетом Волгоградской области, регистрационный номер IRB 00005839 IORG 0004900 (OHRP). Заключение: «Исследование запланировано в соответствии с принципами биоэтики. В ходе исследования будет получено информированное согласие испытуемых по установленной форме, не будут нарушены принципы конфиденциальности и уважения автономии личности, испытуемым не будет причинен вред, не вызванный необходимостью». Протокол № 209 - 2015 от 09 февраля 2015 г.

\section{Статистический анализ}

\section{Принципы расчета размера выборки}

Размер выборки для определения количества пациентов стоматологических организаций - участников скринингового исследования был рассчитан по формуле: $\mathrm{n}=(\mathrm{t} 2 \mathrm{pqN}) /(\Delta 2 \mathrm{~N}+\mathrm{t} 2 \mathrm{pq})$, где $\mathrm{t}=2$ (значение критерия Стьюдента при вероятности ошибки не более 5\%); р - величина показателя (\%), q=100-p (максимальное значение pq=50х50=2500); $\mathrm{N}$ - генеральная совокупность (среднее количество первичных пациентов одной стоматологической организации в течение периода анкетирования - 193 человека); $\Delta$ - предельная ошибка показателя (5\%). В соответствии с расчетами размер выборки в одной стоматологической организации должен составлять 88 человек. В нашем исследовании, проводившемся в двух стоматологических организациях, приняли участие 204 пациента. Расчет размера выборки для проведения анкетирования пациентов с воспалительными заболеваниями пародонта с целью оценки их знаний и комплаентности не проводился. Размер выборки для анкетирования врачей предварительно не рассчитывали, в исследовании участвовали 41,89\% (62 из 148) врачей-эндокринологов и 26,01\% врачей-стоматологов (371 из 1426), работавших в Волгоградской области.

Методы статистического анализа данных: использовали программное обеспечение Microsoft Excel 2010 и стандартные методы вариационной статистики, рассчитывали относительные и средние величины: частота признаков (\%), величина среднего значения (М), величина ошибки стандартного отклонения среднего значения (m). Значимость (p) различий определяли по критерию Стьюдента (t), различия считали существенными при $\mathrm{t}>2$, $p<0,05$.

\section{РЕЗУЛЬТАТЬ}

Объекты (участники) исследования

Характеристика пациентов - участников исследования представлена в табл. 1. В исследовании знаний и комплаентности приняли участие 228 пациентов, обратившихся в пародонтологические кабинеты по поводу воспалительных заболеваний пародонта. Среди них преобладали женщины (77,63\%), что отражает типичный гендерный состав пациентов, посещающих стоматологические организации для лечения воспалительных заболеваний пародонта. Большинство пациентов с воспалительными заболеваниями пародонта находились в возрасте 45-64 лет, что соответствовало эпидемиологическим данным о распространенности заболеваний пародонта среди населения России [11]. Уменьшение числа пациентов в возрасте 65 лет и старше отражало снижение потребности населения в пародонтологическом лечении, что обусловлено потерей зубов [11]. По социальному составу большинство $(61,84 \%)$ респондентов были работающими в различных сферах, что отражает социальную важность проблемы СД. Более четверти $(27,19 \%)$ респондентов составляли пенсионеры, 7,45\% - временно не работали, 3,5\% - находились на инвалидности.

Среди 204 стоматологических пациентов, принимавших участие в скрининговом обследовании и имевших различные причины для посещения врача-стоматолога, также преобладали женщины и пациенты трудоспособного возраста (см. табл. 1).

Характеристика врачей, участвовавших в исследовании, представлена в табл. 2. Среди врачей-стоматологов (371), участвовавших в исследовании, немногим более половины $(54,17 \%)$ работали в государственных, осталь- 
Таблица 1. Характеристика пациентов, участвовавших в исследовании

\begin{tabular}{|c|c|c|c|c|c|c|c|}
\hline \multirow{3}{*}{ Группа } & \multicolumn{2}{|c|}{ Пол } & \multicolumn{5}{|c|}{ Возраст в годах } \\
\hline & женский & мужской & $25-34$ & $35-44$ & $45-54$ & $55-64$ & $\geq 65$ \\
\hline & $\%$ & $\%$ & $\%$ & $\%$ & $\%$ & $\%$ & $\%$ \\
\hline $\begin{array}{l}\text { Пациенты с воспалительными } \\
\text { заболеваниями пародонта - } \\
\text { исследование комплаентности, } 228 \text { чел. }\end{array}$ & 77,63 & 22,36 & 7,89 & 15,35 & 35,96 & 31,57 & 9,21 \\
\hline $\begin{array}{l}\text { Стоматологические пациенты - } \\
\text { скрининговое анкетирование, } 204 \text { чел. }\end{array}$ & 62,40 & 35,80 & 9,31 & 25,98 & 38,23 & 24,01 & 2,45 \\
\hline
\end{tabular}

Таблица 2. Характеристика врачей, участвовавших в исследовании

\begin{tabular}{lccccc}
\hline \multirow{2}{*}{ Группы врачей, $\mathbf{n}$} & \multicolumn{2}{c}{ Организации } & \multicolumn{2}{c}{ Стаж работы (годы) } \\
\cline { 2 - 6 } & государственная & негосударственная & $\leq 10$ & $\mathbf{1 1 - 2 0}$ & $>\mathbf{2 0}$ \\
\cline { 2 - 6 } & \% & \% & \% & \% \\
\hline Стоматологи, 371 чел. & 54,17 & 45,82 & 32,61 & 45,01 & 22,37 \\
Эндокринологи, 62 чел. & 85,48 & 14,52 & 37,09 & 41,93 & 20,98 \\
\hline
\end{tabular}

ные $45,82 \%$ - в негосударственных стоматологических организациях. Среди врачей-эндокринологов (62) большинство $(85,48 \%)$ работали в государственных медицинских организациях. Около трети (32,61\%) стоматологов и немногим более трети (37,09\%) эндокринологов имели стаж работы до 10 лет, остальные - более 10 лет. Таким образом, врачи - участники исследования работали в организациях различных форм собственности, и большинство из них имели значительный опыт работы по специальности. Большее количество врачей-стоматологов, работавших в негосударственных организациях, по сравнению с врачами-эндокринологами, объясняется тем, что на территории Волгоградской области число негосударственных стоматологических организаций, где работают врачи-стоматологи, значительно больше числа негосударственных медицинских организаций, где работают врачи-эндокринологи.

\section{Основные результаты исследования}

Изучение данных анкетирования пациентов с воспалительными заболеваниями пародонта (табл. 3) показало, что большинство из них более 10 лет страдали воспалительными заболеваниями пародонта (65,35\% ответов) и многие имели диагностированный диабет (59,64\%).

Однако лишь менее половины - 42,10\% - респондентов сообщили, что врач-стоматолог интересовался наличием у них СД и рекомендовал обследование у врача-эндокринолога. Среди пациентов, страдавших воспалительными заболеваниями пародонта и отрицавших наличие диабета, лишь 19,56\% планировали пройти эндокринологическое обследование. Среди тех, кто получил направление на эндокринологическое обследование, лишь каждый шестой - 17,70\% - прошел данное обследование. Пациенты с воспалительными заболеваниями пародонта признавали в основном возможность негативного влияния СД на стоматологическое здоровье (54,38\% ответов), и лишь немногие $(10,08 \%)$ понимали, что воспалительные заболевания пародонта могут ухудшать течение СД. Большинство (85,09\%) респондентов обращались к врачу-стоматологу нерегулярно. Получен- ные данные свидетельствуют о недостаточности знаний о СД, низком уровне комплаентности пациентов с воспалительными заболеваниями пародонта и недостаточном внимании к проблеме СД на приеме пародонтолога.

Результаты анкетирования врачей представлены в табл. 4. Анализ полученных данных показал, что большинство врачей-стоматологов $(51,75 \%)$ и эндокринологов (62,9\%) признавали, что СД ухудшает стоматологическое здоровье пациентов, однако влияние стоматологических заболеваний на течение диабета или их взаимосвязь осознавались врачами значительно реже. О наличии диабета врачи-стоматологи спрашивали каждого своего пациента значительно реже, чем врачи-эндокринологи - о наличии у больных СД стоматологических заболеваний. В то же время многие врачи редко или совсем не интересовались этими проблемами своих пациентов (70,86\% ответов стоматологов и 37,09\% ответов эндокринологов). Между тем на вопрос о направлении своих пациентов на обследование к коллегам более половины респондентов-стоматологов и более трети респондентов-эндокринологов утверждали, что делают это всегда или часто (51,75\% и 35,48\% соответственно). Однако почти все респонденты редко или совсем не координировали с коллегами свои назначения больным СД $(93,34 \%$ ответов стоматологов и $85,48 \%$ ответов эндокринологов). Таким образом, полученные данные подтверждают недостаточный уровень понимания проблемы взаимовлияния СД и стоматологических заболеваний и низкий уровень междисциплинарного взаимодействия врачей-стоматологов и врачей-эндокринологов.

Результаты скринингового анкетирования, проведенного в двух стоматологических организациях, позволили выявить среди пациентов, отрицавших у себя наличие СД, многочисленную (64,21\%) группу риска предиабета или СД 2 типа (табл. 5). Настораживает, что около трети (32,85\%) пациентов имели высокий и очень высокий риск СД, чаще в области, чем в Волгограде (35,41\% и 30,55\% соответственно, хотя различия не были существенными статистически, $\mathrm{p}>0,05)$. В результате клинического обследования воспалительные заболевания пародонта были выявлены у всех пациентов, которым 
Таблица 3. Данные анкетирования пациентов с воспалительными заболеваниями пародонта

\begin{tabular}{|c|c|c|c|}
\hline \multirow{2}{*}{ Вопросы } & \multirow{2}{*}{ Варианты ответов } & \multicolumn{2}{|c|}{ Частота ответов } \\
\hline & & a6c. & $\%$ \\
\hline \multirow{3}{*}{$\begin{array}{l}\text { Как долго Вы имеете воспалительное } \\
\text { заболевание десен? }\end{array}$} & всегда & 64 & 28,07 \\
\hline & свыше 10 лет & 85 & 37,28 \\
\hline & 5-10 лет & 79 & 34,64 \\
\hline \multirow{3}{*}{ Вы посещаете врача-стоматолога: } & регулярно & 34 & 14,91 \\
\hline & нерегулярно, от случая к случаю & 89 & 39,03 \\
\hline & нерегулярно, когда есть время & 105 & 46,05 \\
\hline \multirow{3}{*}{ Страдаете ли Вы диабетом? } & да & 136 & 59,64 \\
\hline & нет & 43 & 18,85 \\
\hline & не знаю & 49 & 21,49 \\
\hline \multirow{3}{*}{$\begin{array}{l}\text { Интересовался ли стоматолог наличием } \\
\text { у Вас диабета? }\end{array}$} & я сам сообщил ему об этом & 74 & 32,45 \\
\hline & да & 96 & 42,10 \\
\hline & нет & 58 & 25,43 \\
\hline \multirow{2}{*}{$\begin{array}{l}\text { Направил ли Вас стоматолог } \\
\text { на эндокринологическое обследование? }\end{array}$} & да & 96 & 42,10 \\
\hline & нет & 132 & 57,89 \\
\hline \multirow{2}{*}{$\begin{array}{l}\text { Если у Вас нет диагноза «диабет», } \\
\text { но есть воспаление десен, планируете } \\
\text { ли Вы пройти эндокринологическое } \\
\text { обследование? (92 чел.) }\end{array}$} & да & 18 & 19,56 \\
\hline & нет & 74 & 80,43 \\
\hline \multirow{2}{*}{$\begin{array}{l}\text { Если Вас направляли, то прошли ли Вы } \\
\text { эндокринологическое обследование? } \\
\text { (96 чел.) }\end{array}$} & да & 17 & 17,70 \\
\hline & нет & 79 & 82,29 \\
\hline \multirow{4}{*}{$\begin{array}{l}\text { По Вашему мнению, есть ли взаимосвязь } \\
\text { стоматологических заболеваний } \\
\text { и диабета? }\end{array}$} & да, диабет ухудшает стоматологическое здоровье & 124 & 54,38 \\
\hline & $\begin{array}{c}\text { да, стоматологические заболевания ухудшают течение } \\
\text { диабета }\end{array}$ & 23 & 10,08 \\
\hline & нет связи & 41 & 17,98 \\
\hline & не знаю & 40 & 17,54 \\
\hline
\end{tabular}

установили различную степень риска СД по данным скринингового анкетирования.

\section{Дополнительные результаты исследования}

Сравнительный анализ данных анкетирования врачей (см. табл. 4) показал, что стоматологи существенно реже, чем эндокринологи, признавали взаимозависимость СД и стоматологических заболеваний, интересовались наличием у своих пациентов сопутствующих заболеваний. Эндокринологи существенно ( $p<0,001)$ реже, чем стоматологи, считали, что стоматологические заболевания могут ухудшать течение СД. Ответы эндокринологов о редкой координации лечения больных со стоматологом встречались существенно ( $p<0,001)$ чаще, чем ответы стоматологов о координации с эндокринологом лечения своих пациентов с СД. В частоте остальных ответов статистически значимых различий выявлено не было.

Сравнительный анализ данных скринингового анкетирования стоматологических пациентов (см. табл. 5) выявил существенные различия по частоте умеренного риска предиабета и СД 2 типа, который у жителей г. Волгограда встречался существенно $(p<0,001)$ чаще, чем у жителей области. Общий риск развития диабета у жителей Волгограда был немного выше, чем у жителей области, однако различия не были статистически значимыми. Слегка повышенный и высокий риск СД встречался у жителей области незначительно ( $>0,05)$ чаще, чем у жителей Волгограда. Очень высокий риск у жителей Волгограда и области встречался одинаково часто.

\section{Нежелательные явления}

В ходе исследования не было зарегистрировано нежелательных явлений.

\section{ОБСУЖДЕНИЕ}

Достоинством проведенного исследования можно назвать анализ проблемы СД с точки зрения междисциплинарного взаимодействия врачей. Несмотря на то что исследование ограничено рамками одного региона, можно предположить типичность выявленных явлений для российского здравоохранения.

\section{Резюме основного результата исследования}

Результаты исследования выявили недостаточный уровень взаимодействия врачей-стоматологов и эндокринологов при выявлении и ведении пациентов с СД, 
Таблица 4. Данные анкетирования врачей-стоматологов и врачей-эндокринологов

\begin{tabular}{|c|c|c|c|c|c|}
\hline \multirow{3}{*}{ Вопросы } & \multirow{3}{*}{ Варианты ответов } & \multicolumn{4}{|c|}{ Частота ответов } \\
\hline & & \multicolumn{2}{|c|}{ стоматологи } & \multicolumn{2}{|c|}{ эндокринологи } \\
\hline & & aбc. & $\%$ & абc. & $\%$ \\
\hline \multirow{4}{*}{$\begin{array}{l}\text { По Вашему мнению, } \\
\text { есть ли взаимосвязь } \\
\text { стоматологических } \\
\text { заболеваний и диабета? }\end{array}$} & $\begin{array}{c}\text { да, диабет ухудшает стоматологическое } \\
\text { здоровье }\end{array}$ & 192 & 51,75 & 39 & 62,90 \\
\hline & $\begin{array}{c}\text { да, стоматологические заболевания } \\
\text { ухудшают течение диабета }\end{array}$ & 119 & 32,07 & 5 & $8,06^{*}$ \\
\hline & заболевания взаимозависимы & 21 & $5,66^{* *}$ & 12 & $19,35^{* *}$ \\
\hline & нет связи & 39 & 10,51 & 6 & 9,67 \\
\hline \multirow{3}{*}{$\begin{array}{l}\text { Интересовались ли Вы } \\
\text { наличием у пациентов } \\
\text { сопутствующих заболеваний?* }\end{array}$} & всегда или часто & 108 & $29,11^{* *}$ & 39 & $62,9 * *$ \\
\hline & редко & 254 & $68,46^{* *}$ & 15 & $24,19^{* *}$ \\
\hline & нет & 9 & 2,42 & 8 & 12,90 \\
\hline \multirow{3}{*}{$\begin{array}{l}\text { Как часто Вы направляете } \\
\text { своих пациентов на } \\
\text { обследование к коллегам?* }\end{array}$} & всегда или часто & 192 & 51,75 & 22 & 35,48 \\
\hline & редко & 134 & 36,11 & 29 & 46,77 \\
\hline & не направляю & 45 & 12,12 & 11 & 17,74 \\
\hline \multirow{3}{*}{$\begin{array}{l}\text { Как часто Вы координируете } \\
\text { лечение своих пациентов } \\
\text { с коллегами?* }\end{array}$} & всегда или часто & 24 & 6,46 & 9 & 14,51 \\
\hline & редко & 131 & $35,30 * *$ & 46 & $74,19^{* *}$ \\
\hline & никогда & 216 & $58,22^{* *}$ & 7 & $11,29 * *$ \\
\hline
\end{tabular}

Примечания: * Стоматологов спрашивали, интересуются ли они наличием у пациентов диабета, направляют ли пациентов с воспалительными заболеваниями пародонта на обследование к эндокринологу, координируют ли с эндокринологом стоматологическое лечение больных СД; Эндокринологов спрашивали, интересуются ли они наличием стоматологических заболеваний у больных СД, направляют ли больных СД на обследование к стоматологу, координируют ли лечение больных СД с врачом-стоматологом. ** Наличие существенных (р<0,01) различий между частотами ответов врачей-стоматологов и врачей-эндокринологов.

Таблица 5. Результаты скрининга стоматологических пациентов на риск предиабета или сахарного диабета 2 типа

\begin{tabular}{lcccccc}
\hline \multirow{2}{*}{$\begin{array}{c}\text { Степень риска } \\
\text { предиабета }\end{array}$} & \multicolumn{3}{c}{ Количество пациентов с выявленным риском предиабета или СД2 } \\
\cline { 2 - 7 } \multicolumn{1}{c}{ или СД2 } & \multicolumn{2}{c}{ Волгоград, $\mathbf{N = 1 0 8}$} & \multicolumn{2}{c}{ Котельниково, $\mathbf{N = 9 6}$} & \multicolumn{2}{c}{ Всего, N=204 } \\
\cline { 2 - 7 } & абс. & \% & абс. & \% & абс. & \% \\
\hline Слегка повышенный & 13 & 12,04 & 16 & 16,67 & 29 & 14,21 \\
Умеренный & 27 & $25,00^{*}$ & 8 & $8,33^{*}$ & 35 & 17,16 \\
Высокий & 16 & 14,81 & 19 & 19,79 & 35 & 17,16 \\
Очень высокий & 17 & 15,74 & 15 & 15,62 & 32 & 15,69 \\
Всего & 73 & 67,59 & 58 & 60,42 & 131 & 64,21 \\
\hline
\end{tabular}

Примечание: * Наличие существенных $($ <<0,01) различий между показателями жителей Волгограда и области. Сд2 - сахарный диабет 2 типа.

низкий уровень знаний и комплаентности стоматологических пациентов в отношении эндокринологического обследования, подтвердили возможности на стоматологическом приеме скрининга риска СД.

\section{Обсуждение основного результата исследования}

В нашем исследовании установлена недостаточность знаний врачей-стоматологов, врачей-эндокринологов, больных диабетом и стоматологических пациентов о взаимовлиянии диабета и стоматологических заболеваний. Аналогичные заключения имеются в работах других авторов. Так, I.B. Lamster сообщает о том, что нестоматологический медицинский персонал не придает должного значения индуцируемым диабетом заболеваниям полости рта, которые снижают качество жизни больных, прямо и опосредованно влияют на контроль гликемии [12]. R. Al-Habashneh et al. установили, что две трети врачей не осознают, что заболевания пародонта затрудняют метаболический контроль диабета, и только половина врачей направляют больных диабетом на обследование и лечение к стоматологам [13]. С другой стороны, в исследовании K. Forbes et al. было показано, что большинство стоматологов общей практики пассивны в ведении пациентов с СД, только 25,6\% стоматологов направляли на эндокринологическое обследование пациентов с подозрением на диабет, всего 2,6\% проводили скрининг содержания глюкозы в капиллярной крови пациентов, а треть стоматологов сообщили о нежелании проводить подобный скрининг [14].

Недостаточность знаний о взаимовлиянии диабета и стоматологических заболеваний, выявленная в нашем исследовании, способствовала низкому уровню комплаентности пациентов и нерегулярности посещений врача-стоматолога. Подобный недостаток знаний был выяв- 
лен H.K. Yuen et al. более чем у половины обследованных пациентов с СД [15]. По мнению M.D. Macek, S.L. Tomar, нехваткой знаний объяснялась меньшая частота посещений врача-стоматолога у больных диабетом по сравнению с пациентами без СД [16]. По-видимому, улучшить данную ситуацию могли бы занятия в Школах сахарного диабета, направленные на просвещение больных СД в отношении влияния диабета на развитие и течение стоматологических заболеваний, влияния стоматологических заболеваний на течение СД. Такие занятия могли бы повысить мотивацию больных СД к профилактике и лечению основных стоматологических заболеваний, что, в свою очередь, улучшило бы метаболический контроль диабета.

Поскольку междисциплинарное взаимодействие при ведении больных диабетом не получило широкого распространения, рекомендуется улучшить сотрудничество между диабетологами и стоматологами [17]. Стоматологическая помощь должна стать частью медицинской помощи больным диабетом. Международная диабетическая федерация рекомендует регулярно разъяснять больным СД важность стоматологической помощи и контроля состояния десен, гигиенического ухода за зубами, ежегодно направлять больных СД к стоматологу на обследование и лечение [18]. В стандартах медицинской помощи больным диабетом, опубликованных Американской ассоциацией диабетологов, рекомендуется проводить скрининг на диабет пациентов стоматологических клиник [19].

По данным Национального эпидемиологического исследования (NATION), в России диабет своевременно не диагностируется более чем у 3,8\% сельского населения и 2,7\% городского населения, что приводит к повышению риска развития у них осложнений. В связи с этим возрастает необходимость разработки государственных скрининговых программ выявления СД, особенно в группах риска $[2,20]$. Учитывая связь СД и стоматологических заболеваний, пациентов с воспалительными заболеваниями пародонта можно отнести к группе риска по диабету [21]. Исследование полезности подобных скринингов показало, что у 30\% пациентов старше 30 лет, которых опрашивали в стоматологических клиниках с последующим направлением к врачам общей практики, была выявлена дисгликемия [22]. Проведенный нами скрининг выявил риск предиабета и СД 2 типа у большинства стоматологических пациентов, причем у трети из них риск был высокого и очень высокого уровня. Подобные исследования, проведенные ранее в нашем регионе среди соматических пациентов, выявили риск СД у 71,1\% участников анкетирования, высокий и очень высокий риск - у 21,7\%. У 4,8\% обследованных был подтвержден диагноз СД 2 типа после исследования уровня глюкозы крови $[23,24]$. Большее, по сравнению с соматическими пациентами, количество лиц с высоким и очень высоким риском СД (32,8\%), выявленное нами среди стоматологических пациентов, еще раз подчеркивает взаимосвязь заболеваний полости рта и диабета, важность скринингового обследования на диабет пациентов стоматологических организаций.

Применение скринингового анкетирования в стоматологической практике позволяет привлечь внимание пациентов к проблеме недиагностированного диабета и повысить их мотивацию к эндокринологическому обследованию, а у больных диабетом - повысить внимание к гликемическому контролю и своевременной коррекции лечения у эндокринолога. Повышение мотивации к контролю гликемии необходимо, так как в настоящее время только менее трети больных СД проходят необходимый мониторинг [8].

\section{Ограничения исследования}

Ограничения исследования обусловлены тем, что данные о знаниях врачей и пациентов, о поведенческих привычках пациентов и действиях врачей в отношении менеджмента больных диабетом были получены в результате самооценки респондентов, а не путем тестирования и включенного наблюдения. Ограничения скринингового анкетирования пациентов также обусловлены самооценкой.

\section{ЗАКЛЮЧЕНИЕ}

Проведенные ранее исследования показали взаимовлияние и взаимозависимость СД и стоматологических заболеваний. Однако этой проблеме уделяется недостаточное внимание в основополагающих руководствах для врачей-стоматологов и врачей-эндокринологов. Анализ данных, полученных в ходе исследования, позволил выявить недостаточный уровень междисциплинарного взаимодействия врачей-стоматологов и врачей-эндокринологов при выявлении и ведении больных СД, недостаточную мотивацию стоматологических пациентов к проведению эндокринологического обследования. Скрининговое анкетирование выявило высокую частоту повышенного риска (высокий и очень высокий риск) СД у 32,85\% пациентов стоматологических клиник. Скрининг стоматологических пациентов (анкетирование на выявление риска СД с применением «Опросника...», предложенного в Алгоритмах специализированной медицинской помощи больным сахарным диабетом под редакцией И.И. Дедова и соавт., 2013-2017) может повысить мотивацию пациентов к эндокринологическому обследованию, частоту выявления скрытых форм диабета, улучшить метаболический контроль у больных СД. Полученные данные актуализируют необходимость улучшения взаимодействия врачей-стоматологов и врачей-эндокринологов в решении проблемы СД. Скрининг на определение риска СД целесообразно включить в алгоритм обследования больных с воспалительными заболеваниями пародонта. В перечень специалистов, консультация которых обязательна при ведении больных с диагнозом СД, необходимо ввести врачей-стоматологов. Целесообразно нормативное закрепление в соответствующих клинических протоколах необходимости взаимодействия эндокринологов и стоматологов в ведении больных с СД. Для улучшения мотивации больных СД к стоматологическому обследованию и лечению необходимо ввести занятия стоматологического профиля в Школу сахарного диабета.

\section{ДОПОЛНИТЕЛЬНАЯ ИНФОРМАЦИЯ}

Источник финансирования. Финансирование осуществлялось в рамках научно-исследовательской программы ФГБОУ ВО «Волго- 
градский государственный медицинский университет» Минздрава России.

Конфликт интересов. Авторы декларируют отсутствие явных и потенциальных конфликтов интересов, связанных с публикацией настоящей статьи.

Участие авторов. Маслак Е.Е. - концепция и дизайн исследования, анализ полученных данных, написание текста; Наумова В.Н. - сбор и обработка материалов, анализ полученных данных, написание текста. Все авторы внесли существенный вклад в проведение исследования и подготовку статьи, прочли и одобрили финальную версию перед публикацией.

Благодарности. Благодарим главного врача стоматологической поликлиники Волгоградского государственного медицинского университета к.м.н. Михальченко Алексея Валерьевича; главного врача ГАУЗ «Котельниковская стоматологическая поликлиника» Журавлёва Сергея Николаевича за помощь в организации исследования.

\section{СПИСОК ЛИТЕРАТУРЫ | REFERENCES}

1. NCD Risk Factor Collaboration (NCD-RisC). Worldwide trends in diabetes since 1980: a pooled analysis of 751 population-based studies with 4.4 million participants. Lancet. 2016;387(10027):1513-1530. doi: 10.1016/s0140-6736(16)00618-8

2. Дедов И.И., Шестакова М.В., Викулова О.К. Эпидемиология сахарного диабета в Российской Федерации: клинико-статистический отчет по данным Федерального регистра сахарного диабета // Сахарный диабет. — 2017. - T. 20. — №1. — C. 13-41. [Dedov II, Shestakova MV, Vikulova OK. Epidemiology of diabetes mellitus in Russian Federation: clinical and statistical report according to the federal diabetes registry. Diabetes mellitus. 2017;20(1):13-41. (In Russ.)] doi: 10.14341/DM8664

3. Mauri-Obradors E, Estrugo-Devesa A, Jane-Salas E, et al. Oral manifestations of Diabetes Mellitus. A systematic review. Med Oral Patol Oral Cir Bucal. 2017;22(5):e586-e594. doi: 10.4317/medoral.21655

4. Шестакова М.В., Дедов И.И. Сахарный диабет в Российской Федерации: аргументы и факты // Терапевтический архив. - 2016. - T. 88. — №10. - C. 4-8. [Shestakova MV, Dedov II. Diabetes mellitus in the Russian Federation: Arguments and facts. Ter Arkh. 2016;88(10):4-8. (In Russ.)] doi: 10.17116/terarkh201688104-8

5. Pumerantz AS, Bissett SM, Dong F, et al. Standardized screening for periodontitis as an integral part of multidisciplinary management of adults with type 2 diabetes: an observational cross-sectional study of cohorts in the USA and UK. BMJ Open Diabetes Res Care. 2017;5(1):e000413. doi: 10.1136/bmjdrc-2017-000413

6. Наумова В.Н., Маслак Е.Е. Сахарный диабет и стоматологическое здоровье: проблемы диагностики и лечения пациентов стоматологических клиник. // Практическая медицина. - 2013. №4. - C. 10-14. [Naumova VN, Maslak EE. Diabetes mellitus and dental health: problems in diagnosis and treatment of dental clinics' patients. Prakticheskaya meditsina. 2013;(4):10-14. (In Russ.)]

7. Рунге Р.И. Новые подходы к организации стоматологической помощи больным сахарным диабетом // Врач-аспирант. 2013. - T. 58. — №3.1. — C. 163-168. [Runge RI. New approaches to the organization of the dental medical care for the patients with diabetes. Vrach-aspirant. 2013;58(3.1):163-168. (In Russ.)]

8. Дедов И.И., Шестакова М.В., Майоров А.Ю., и др. Алгоритмы специализированной медицинской помощи больным сахарным диабетом. / Под ред. Дедова И.И., Шестаковой М.В., Майорова А.Ю. - 8-й выпуск // Сахарный диабет. - 2017. - Т. 20. №1S. - C. 1-121. [Dedov II, Shestakova MV, Mayorov AY, et al. Dedov II, Shestakova MV, Mayorov AY, editors. Standards of specialized diabetes care. 8th ed. Diabetes mellitus. 2017;20(1S):1-121. (In Russ.)] doi: 10.14341/DM20171S8

9. Терапевтическая стоматология. Начиональное руководство. / Под ред. Дмитриевой Л.А., Максимовского Ю.М. - М.: ГЭОТАР-Медиа; 2015. [Dmitrieva LA, Maksimovskiy YM, editors. Terapevticheskaya stomatologiya. Natsional'noe rukovodstvo. Moscow: GEOTAR-Media; 2015. (In Russ.)]

10. Седова Н.Н., Навроцкий Б.А., Волчанский М.Е., и др. Теория и практика применения качественных методов социологии в медицине // Медицинский Вестник Северного Кавказа. - 2015. - Т. 10. №3. - C. 327-331. [Sedova NN, Navrotsky BA, Volchansky ME, et al. Theory and practice of application of qualitative sociological methods in medicine. Medical news of North Caucasus. 2015;10(3):327-331. (In Russ.)] doi: 10.14300/mnnc.2015.10078
11. Кузьмина Э.М., Кузьмина И.Н., Васина С.А., Смирнова Т.А. Стоматологическая заболеваемость населения России. Состояние твердых тканей зубов. Распространенность зубочелюстных аномалий. Потребность в протезировании. - М.: МГМСУ; 2009. [Kuz’ mina EM, Kuz` mina IN, Vasina SA, Smirnova TA. Stomatologicheskaya zabolevaemost' naseleniya Rossii. Sostoyanie tverdykh tkaney zubov. Rasprostranennost' zubochelyustnykh anomaliy. Potrebnost'v protezirovanii. Moscow: MGMSU; 2009. (In Russ.)]

12. Lamster, IB. Diabetes and oral health. What's their relationship? Diabetes Self Manag. 2012;29(3):32-34.

13. Al-Habashneh R, Barghout N, Humbert $L$, et al. Diabetes and oral health: doctors' knowledge, perception and practices. J Eval Clin Pract. 2010;16(5):976-80. doi: 10.1111/j.1365-2753.2009.01245.x

14. Forbes K, Thomson WM, Kunzel C, et al. Management of patients with diabetes by general dentists in New Zealand. J Periodontol. 2008;79(8):1401-1408. doi: 10.1902/jop.2008.070640

15. Yuen HK, Wolf BJ, Bandyopadhyay D, et al. Oral health knowledge and behavior among adults with diabetes. Diab Res Clin Pract. 2009;86(3):239-246. doi: 10.1016/j.diabres.2009.09.010

16. Macek MD, Tomar SL. Dental care visits among dentate adults with diabetes and periodontitis. J Pub Health Dent. 2009;69(4):284-289. doi: 10.1111/j.1752-7325.2009.00136.x

17. Owens JB, Wilder RS, Southerland JH, et al. North Carolina internists' and endocrinologists' knowledge, opinions, and behaviors regarding periodontal disease and diabetes: need and opportunity for interprofessional education. J Dent Educ. 2011;75(3):329-338.

18. International Diabetes Federation. IDF Guideline on oral health for people with diabetes. Brussels: IDF; 2009.

19. American Diabetes Association. Standards of medical care in diabetes - 2017. 2. Classification and Diagnosis of Diabetes. Diabetes Care. 2017;40(Suppl 1):S11-S24. doi: 10.2337/dc17-S005

20. Дедов И.И., Шестакова М.В., Галстян Г.Р. Распространенность сахарного диабета 2 типа у взрослого населения России (исследование NATION) // Сахарный диабеm. - 2016. - T. 19. — №2. — C. 104-112. [Dedov II, Shestakova MV, Galstyan GR. The prevalence of type 2 diabetes mellitus in the adult population of Russia (NATION study). Diabetes mellitus. 2016;19(2):104-112. (In Russ.)] doi: 10.14341/DM20041 16-17

21. Lalla E, Cheng B, Kunzel C, et al. Dental findings and identification of undiagnosed hyperglycemia. J Dent Res. 2013;92(10):888-892. doi: $10.1177 / 0022034513502791$

22. Herman WH, Taylor GW, Jacobson JJ, et al. Screening for prediabetes and type 2 diabetes in dental offices. J Public Health Dent. 2015;75(3):175-182. doi: 10.1111/jphd.12082

23. Сабанов В.И., Дьяченко Т.С., Горбаткова И.В., Бердник Е.Ю. Эффективность скрининг-анкетирования по выявлению среди населения сахарного диабета II типа // Волгоградский научно-медицинский журнал. - 2010. - №4. - C. 23-26. [Sabanov VI, Djachenko TS, Gorbatkova IV, Berdnik EJ. Effectivness of screening questionnaire identifying the populations with type II diabetes. Volgogradskii nauchno-meditsinskii zhurnal. 2010;(4):23-26. (In Russ.)]

24. Сабанов А.В., Горбаткова И.В., Дьяченко Т.С., Бердник Е.Ю. Территориальный регистр сахарного диабета в Волгоградской области за 2006-2010 гг. // Волгоградский научно-медицинский журнал. 2011. - №1. - C. 60-62. [Sabanov AV, Gorbatkova IV, Djachenko TS, Berdnik EJ. The territorial register of diabetes in the volgograd region over the years 2006-2010. Volgogradskii nauchno-meditsinskii zhurnal. 2011;(1):60-62. (In Russ.)] 


\section{ИНФОРМАЦИЯ ОБ АВТОРАХ [AUTHORS INFO]}

*Наумова Виктория Николаевна, К.м.Н., доцент [Victoria N. Naumova, MD, PhD, associate professor]; адрес: 400131, Волгоград, пл. Павших Борцов, д. 1 [address: 1, Pavshih borcov sq., Volgograd, 400131 Russian Federation]; ORCID: http://orcid.org/0000-0001-5629-9337; eLibrary SPIN: 4281-1723; e-mail: vika@as.ru

Маслак Елена Ефимовна, д.М.н., професcop [Elena E. Maslak, MD, PhD, Professor];

ORCID: http://orcid.org/0000-0003-2011-9714; eLibrary SPIN: 9375-5320; e-mail: eemaslak@yandex.ru

\section{ЦИТИРОВАТЬ:}

Маслак Е.Е., Наумова В.Н. Сотрудничество врачей-стоматологов и врачей-эндокринологов по вопросам выявления и ведения пациентов с сахарным диабетом: аспекты междисциплинарного взаимодействия // Сахарный диабет. 2019. — T. 22. — №1. — C. 35-43. doi: 10.14341/DM9581

\section{TO CITE THIS ARTICLE:}

Maslak EE, Naumova VN. Interdisciplinary cooperation between dentists and endocrinologists for identification and management of diabetes mellitus. Diabetes Mellitus. 2019;22(1):35-43. doi: 10.14341/DM9581 